1 Fundação Oswaldo Cruz (Fiocruz), Instituto Nacional de Saúde da Mulher, da Criança e do Adolescente Fernandes Figueira (IFF), Núcleo de Comunicação Social - Rio de Janeiro (RJ), Brasil. irenekalil@gmail.com

2 Fundação Oswaldo Cruz (Fiocruz), Instituto de Comunicação e Informação Científica e Tecnológica em Saúde (Icict) - Rio de Janeiro (RJ), Brasil. Universidade do Estado do Rio de Janeiro (Uerj), Instituto de Medicina Social (IMS) - Rio de Janeiro (RJ), Brasil. adriana.aguiar@post.harvard. edu

\section{Trabalho feminino, políticas familiares e discursos pró-aleitamento materno: avanços e desafios à equidade de gênero}

\author{
Women's work, family policies and pro-breastfeeding discourses: \\ advances and challenges to gender equity
}

Irene Rocha Kali|1, Adriana Cavalcanti de Aguiar²

RESUMO O artigo aborda a relação entre discursos pró-aleitamento materno, trabalho feminino e políticas familiares no Brasil, apontando avanços e desafios à equidade de gênero. A análise dos materiais da Estratégia de Apoio à Mulher Trabalhadora que Amamenta, do Ministério da Saúde, com base nos referenciais dos estudos de gênero e da semiologia dos discursos sociais, indica como os discursos oficiais reforçam o valor da amamentação para a saúde da criança e reiteram a divisão sexual do trabalho. Por sua vez, as políticas familiares ainda não atendem às necessidades sociais, como a extensão das licenças maternidade e paternidade para todos os trabalhadores e a criação de licenças parentais.

PALAVRAS-CHAVE Aleitamento materno. Trabalho feminino. Políticas públicas. Educação em saúde. Gênero e saúde.

\begin{abstract}
The paper discusses the relationship between pro-breastfeeding discourses, women's work and family policies in Brazil, pointing advances and challenges to gender equity. The analysis of the Strategy to Support Breastfeeding Working Mothers material, of the Ministry of Health, based on benchmarks of gender studies and social discourses semiology, indicates how the official discourses reinforce the value of breastfeeding for children health and reiterate the sexual division of labor. In turn, family policies still don't cover the social needs, such as the extension of maternity and paternity leaves for all workers, and the creation of parental leaves.
\end{abstract}

KEYWORDS Breastfeeding. Women's work. Public policies. Health education. Gender and health. 


\section{Introdução}

O aleitamento materno é prática intensamente estimulada por organizações internacionais e por políticas públicas em diversos países, sendo visto como importante fator na redução das taxas de morbimortalidade infantil e no incremento da saúde da criança. E isso não é uma prerrogativa das chamadas nações 'em desenvolvimento'. Inglaterra, Estados Unidos, Canadá, entre outros, também promovem consistente movimento em prol da adoção maciça da amamentação. Em geral, os discursos oficiais se pautam no valor nutricional e imunológico do leite materno para o bebê/criança, além de enfatizarem seus benefícios na redução das

possibilidades de surgirem problemas alérgicos, respiratórios e também de algumas doenças que costumam se manifestar mais tarde, tais como obesidade, pressão alta, colesterol alto e diabete. (BRASIL, 2010B, P. 11).

Fonte do precioso leite, o corpo feminino é objeto de regulações, agora como instrumento de garantia da saúde da criança em moldes apregoados pelos governos e por organizações internacionais.

Ocorre que mulheres brasileiras de diversos estratos socioeconômicos integram, como componente imprescindível, tanto o sistema 'reprodutivo' (organizado em torno de atividades de gestar, parir, alimentar e cuidar das crianças e da família) quanto o sistema produtivo, como população economicamente ativa. Segundo dados do Instituto Brasileiro de Geografia e Estatística (IBGE), a força de trabalho feminina corresponde a $43,55 \%$ do total, somando 39.870 .376 pessoas. Algumas dessas mulheres trabalhadoras são responsáveis pelo sustento exclusivo de $37,3 \%$ das famílias brasileiras, a maioria delas 'monoparentais', ou seja, compostas pela mãe e seus filhos (IBGE, 2010). Cabe, então, propor uma reflexão sobre como o Estado brasileiro vem promovendo a disponibilidade e a abrangência de políticas públicas voltadas para a família e como tais iniciativas dialogam com os discursos oficiais pró-aleitamento.

\section{Dos objetos, objetivos, premissas e referenciais teórico-metodológicos}

Busca-se, aqui, trazer à tona algumas questões sobre a relação entre os discursos pró-aleitamento materno, o trabalho feminino e as leis de proteção à infância, à maternidade e, mais recentemente, à paternidade. As principais premissas do presente trabalho são: 1) a despeito dos incisivos discursos que buscam promover a amamentação entre mulheres de todas as classes sociais, desde a virada do século XIX para o XX, e da maciça participação das mulheres na força de trabalho, as políticas familiares vigentes no País fornecem insuficiente suporte à mulher que é mãe e trabalhadora (e ao pai que deseja assumir um papel relevante no cuidado com o bebê); e 2) a interface entre trabalho feminino e maternidade/amamentação (em outras palavras, entre a esfera da produção e da reprodução) é negligenciada nos materiais educativos oficiais da área de saúde, sendo o impacto do trabalho na prática da amamentação pouco tematizado, e os impactos da amamentação na trajetória profissional da mulher jamais mencionados.

O objeto empírico é composto de materiais educativos da Política Nacional de Aleitamento Materno do Ministério da Saúde (MS), especificamente referentes à Estratégia de Apoio à Mulher Trabalhadora que Amamenta (folder dirigido a empresários e cartilha voltada a mulheres); e entrevista presencial semiestruturada com a coordenadora das 
Ações de Aleitamento do MS, realizada em agosto de 2014. A escolha deste corpus híbrido deveu-se, em primeiro lugar, ao entendimento de que, nesses materiais selecionados, sobressairiam as relações entre discursos pró-aleitamento, políticas familiares e trabalho feminino, permitindo a observação da influência desses materiais no questionamento ou na reprodução da divisão sexual do trabalho e de outras perspectivas sexistas historicamente presentes em nossa sociedade. Em segundo lugar, considerou-se que a entrevista seria de fundamental importância em três aspectos: 1) no fornecimento de dados do contexto de produção stricto sensu dos materiais; 2) na compreensão mais ampla dos sentidos sobre aleitamento materno propostos nesses e por esses materiais por meio da voz de seus produtores reais; e 3) na observação da tendência de incorporação de elementos distintos e até mesmo contraditórios nos discursos oficiais, demonstrando a polifonia que é inerente a todo discurso, inclusive ao considerado hegemônico. O projeto de pesquisa que resultou neste artigo foi aprovado pelo Comitê de Ética em Pesquisa da Escola Politécnica de Saúde Joaquim Venâncio Fundação Oswaldo Cruz (Fiocruz) (CAAE 30585014.3.0000.5241).

Para realizar a análise de tais discursos, foram adotados dois referenciais teóricos principais. De um lado, buscou-se compreender o processo de naturalização da amamentação, tomada, progressivamente, como função biológica e social da mulher, sobretudo no discurso biomédico, a partir do olhar dos estudos de gênero. Sem desconsiderar os diferentes usos que o termo gênero pode ter na literatura em saúde coletiva, configurando-se como categoria "complexa e multifacetada" (VILLELA; MONTEIRO; VARGAS, 2009, P. 1004), tomou-se tal categoria como aquela que questiona a suposta essência sexual dos conceitos de masculino e feminino, mostrando que se encontram, na verdade, "mergulhados na esfera política, legitimando posições assimétricas na distribuição social do poder entre os sexos" (ROMANI, 1982, P. 65). A despeito de não ser sinônimo da categoria 'sexo' ou se referir unicamente à categoria 'mulher', entende-se que, tendo sua origem no pensamento feminista, o termo

carrega um compromisso político com as muIheres, e a força da sua utilização reside na possibilidade de oferecer novos ângulos de compreensão dos eventos da vida de mulheres e homens que ampliem a autonomia. (VILLELA; MONTEIRO; VARGAS, 2009, P. 1004).

Ao lado dos estudos de gênero, o principal referencial teórico-metodológico foi a semiologia dos discursos sociais (PINTO, 1994). Aplicada ao material empírico por meio da análise de discurso, essa corrente propõe: 1) entender o discurso como constitutivo/ constituinte das relações sociais de poder, atuando na sua manutenção ou mudança; 2) analisar o discurso tomando como base suas marcas ou pistas textuais; 3) problematizar os sentidos privilegiados e naturalizados nesses discursos, relacionando-os às ideologias implicadas, conscientes ou inconscientes, em sua concepção/produção, como consequência necessária da ligação do discurso com suas condições sociais de produção; e 4) pensar a comunicação/ recepção como processo de negociação de sentidos entre sujeitos emissor e receptor. Nessa perspectiva, as presenças e ausências sobre amamentação nos discursos oficiais estão relacionadas aos contextos ou condições sociais de produção dos discursos, que abarcam desde as condições imediatas em que são produzidos (perfil dos produtores, objetivos, formatos, interlocutores a quem se destinam) até referenciais identificados com menos precisão, sob a forma de memória discursiva ou interdiscurso (ORLANDI, 1999). 


\section{Breve histórico das relações entre discursos pró- aleitamento materno, leis de proteção à infância $e$ à maternidade e trabalho feminino no País}

Neste trabalho, as políticas familiares são tomadas como um componente da construção do chamado 'estado de bem-estar social', compreendendo-se a participação da família em seu desenho institucional, ou seja, esse lugar criado para a família como célula da sociedade, extrapolando as relações do âmbito privado e permeando a esfera pública (FLAQUER, 2000). Segundo Flaquer (2000, P. 12), o termo 'política familiar' abrange

um conjunto de medidas públicas destinadas a aportar recursos às pessoas com responsabilidades familiares para que possam desempenhar, nas melhores condições possíveis, as tarefas e atividades derivadas delas, em especial as de atenção a seus filhos menores delas dependentes.

As políticas familiares se operacionalizam, assim, por meio de leis de proteção à infância, à maternidade, à paternidade e à instituição familiar como um todo.

No Brasil, de acordo com Mott (2001), as primeiras ações no âmbito da proteção à infância e à maternidade tiveram início ainda durante a monarquia, quando foram elaborados projetos de lei para regulamentar o trabalho de escravos (inclusive mulheres grávidas e crianças), fiscalizar a atuação das amas de leite, entre outros. Pelo projeto de lei elaborado, em 1822, por José Bonifácio de Andrade e Silva, após completar três meses de gestação, a escrava ficava

proibida de realizar trabalhos pesados e violentos. Após o oitavo mês a atividade deveria ficar restrita ao serviço da casa e depois do parto deveria ter um mês de convalescença.

(MOTT, 2001, P. 206).

Embora esses e outros projetos não tenham sido aprovados, por irem de encontro aos interesses dos senhores de escravos da época, Mott (2001, P. 207) ressalta que a cidade do Rio de Janeiro foi, logo após a proclamação da República, "o primeiro local a regulamentar o trabalho de menores", e também que,

a partir de 1910, em algumas cidades, as professoras primárias obtiveram dois meses de licença maternidade com vencimentos e proibiu-se o trabalho das mulheres no último mês de gravidez e no primeiro do puerpério. (MOTT, 2001, P. 207).

No final do século XIX, observou-se um crescimento da pressão social para que o Estado brasileiro "assumisse a responsabilidade pela promoção do desenvolvimento físico, moral e intelectual de todas as crianças" (BESSE, 1999, P. 104). No decorrer da década de 1890, presenciou-se a extensão da escolarização pública e elementar gratuita, bem como algumas tentativas de regulação do trabalho infantil nas fábricas, notoriamente infringidas pelos empregadores (BESSE, 1999). Nas primeiras décadas do século XX, com apoio de personalidades envolvidas na defesa da infância, o Estado intensificou a criação de leis que protegiam a saúde e a integridade física de crianças e mães: o percurso de institucionalização das leis sociais no País foi longo, "sendo obtido através da luta de homens e mulheres provenientes de diferentes grupos" (MOTT, 2001, P. 205), como a regulamentação da licença maternidade e $o$ estabelecimento da idade mínima de 14 anos para emprego de menores. Besse (1999, P. 107) defende que, se, por um lado, esse foi um período de 'avanços' na legislação em defesa dos direitos das mães e crianças, por outro, as próprias leis que regulavam o trabalho 
feminino eram produto também de uma convergência de interesses: os operários tinham como objetivo manter suas mulheres em casa, enquanto "os que elaboravam as políticas buscavam orientar as energias das mulheres das classes operárias para a construção de famílias nucleares estáveis”, em prol da ordem social.

É também a partir, principalmente, da segunda metade do século XIX, diante de um panorama de grande urbanização e industrialização no País, que começam a ocorrer transformações significativas no comportamento social com relação à amamentação. Como aplicação do receituário higienista - aliança entre médicos e Estado com o objetivo de defender a saúde física e moral das famílias e, consequentemente, o progresso da nação -, o aleitamento ganha conotação de problema nacional (COSTA, 1999). Por colocar em risco a vida das crianças burguesas e se contrapor aos interesses políticos populacionistas da elite da época (decorrentes da necessidade de ocupar importantes vazios demográficos), o aleitamento 'mercenário' (delegado a amas de leite) passa a ser considerado pelo higienismo uma infração às leis da natureza. O Estado moderno interfere no controle demográfico e político da população e promove um processo de 'estatização do indivíduo' (COSTA, 1999), que implicou a ingerência na transformação dos hábitos e condutas da tradição familiar e na reformulação do papel da mulher na família, convertida ao amor pelos filhos e transformada na "mãe higiênica" (COSTA, 1999, P. 255).

O discurso hegemônico, moralizante, preconizava a amamentação como função social da mulher, reforçando o papel que historicamente lhe coube: o de esposa, mãe, dona de casa, responsável pelo cuidado e a manutenção do lar e da família. Nesse contexto, a questão da relação entre amamentação e trabalho feminino tomava proeminência. Segundo Costa (1999, P. 258/261-262), é possível supor que, além de proteger a vida e a saúde das crianças, a pressão do movimento higiênico em defesa da amamentação tinha ainda outras intenções. Sobre os objetivos disciplinares com relação ao comportamento da mãe, por exemplo, "o uso higiênico do tempo livre da mulher na casa" evitava que ela se perdesse no 'ócio' e em 'passatempos' considerados moralmente inadequados; fortalecia a restrição da atuação da mulher ao espaço doméstico, reduzindo a concorrência com o homem no mundo do trabalho (advinda de uma onda de emancipação feminina insuflada pela urbanização); e fomentava a manutenção da coesão do núcleo familiar, buscando-se, por meio da amamentação, "depositar na mulher a responsabilidade pela unidade da família e dar ao homem maior disponibilidade para outras obrigações sociais". Matos (2000) reitera que a substantiva alteração nas relações familiares, com nova atribuição de papéis (sobretudo para as mães), influenciou, de forma crucial, as transformações que conduziram a mulher, cada vez mais, ao âmbito doméstico.

Desse modo, os discursos pró-aleitamento materno do início do século XX concorreram para o acirramento da divisão sexual do trabalho, conceito que, na acepção de Hirata e Kergoat (2007,597/598), emerge da percepção da carga de trabalho, realizada de forma gratuita e 'invisível' socialmente, exercida pelas mulheres não em seu próprio benefício, mas para outros. O trabalho doméstico seria desenvolvido, segundo as autoras, "sempre em nome da natureza, do amor e do dever materno", e se contrapunha, em certa medida, ao trabalho profissional, assalariado, "pensado até então apenas em torno do trabalho produtivo e da figura do trabalhador masculino, qualificado, branco".

Com relação à regulação do trabalho de mulheres e crianças, apenas durante o governo do presidente Getúlio Vargas, em 1932, foram aprovadas leis definitivas, incluindo direitos como a garantia do emprego após a licença maternidade, os intervalos 
para amamentação até a criança completar seis meses e a instalação de creches no local de trabalho em empresas que empreguem mais de 30 mulheres (BESSE, 1999, P. 105). Em 1940, Vargas criou o Departamento Nacional da Criança (DNCr), subordinado ao Ministério da Educação e Saúde e responsável por centralizar a política de assistência à mãe e à criança no País ao longo de 30 anos (BRASIL, 2011). Extinto em 1969, o DNCr foi substituído, no ano seguinte, pela Coordenação de Proteção Materno-Infantil (CPMI), vinculada à Secretaria de Assistência Médica do Ministério da Saúde (BRASIL, 2011), cuja estrutura passou por diversas mudanças ao longo dos anos até chegar à Coordenação-Geral de Saúde da Criança e Aleitamento Materno (CGSCAM) que conhecemos hoje.

Atualmente, a política do Ministério da Saúde, que promove, protege e apoia o aleitamento materno, operacionaliza-se por uma série de estratégias, duas das quais estão ligadas, diretamente, às temáticas deste artigo: $\mathrm{o}$ Apoio à Mulher Trabalhadora que Amamenta e a Proteção Legal ao Aleitamento Materno. A Proteção Legal ao Aleitamento Materno, como o próprio nome indica, compreende um aparato jurídico para garantir o direito de mulheres trabalhadoras de amamentarem seus filhos e para proteger o aleitamento materno. Nesse sentido, o Brasil possui uma legislação específica, com a Norma Brasileira de Comercialização de Alimentos para Lactentes e Crianças de Primeira Infância, Bicos, Chupetas e Mamadeiras (NBCAL), e a Lei $\mathrm{n}^{0} 11.265 / 2006$, que regulamenta a comercialização de alimentos para lactentes e crianças de primeira infância, e, também, a de produtos de puericultura correlatos. Recentemente, a Lei $\mathrm{n}^{\mathrm{o}}$ 11.770/2008 avançou em promover e apoiar o aleitamento exclusivo nos primeiros seis meses de vida do bebê, regulamentando a extensão da licença maternidade, sem prejuízo do emprego ou do salário, para funcionárias públicas federais. No entanto, a adoção da licença maternidade de 180 dias por estados, municípios e empresas privadas não é obrigatória, sendo 'estimulada', no caso da iniciativa privada, por meio de incentivo fiscal concedido pelo governo federal. Já o Apoio à Mulher Trabalhadora que Amamenta é uma iniciativa lançada pelo MS, em 2010, com objetivo de apoiar a mulher trabalhadora na continuidade da amamentação após o final da licença maternidade. Segundo a coordenadora das Ações de Aleitamento Materno, a estratégia surgiu da identificação da necessidade de, além de orientar a mulher para amamentar exclusivamente até os seis meses do bebê, apoiá-la no retorno ao trabalho, mediante 'acolhimento' pelo empregador e/ou gestor e colegas. Assim, nas palavras da própria coordenadora, tal iniciativa 'extrapola o setor saúde' e busca sensibilizar outros segmentos para a importância da amamentação e a decorrente necessidade de auxiliar a mãe trabalhadora que amamenta na conciliação de amamentação e trabalho.

\section{Resultados: discursos pró-aleitamento, trabalho feminino e políticas familiares}

No que concerne aos materiais educativos da Estratégia Apoio à Mulher Trabalhadora que Amamenta, além de uma cartilha voltada a mulheres, há um folder dirigido a empresários. A coordenadora das Ações de Aleitamento Materno informou que, na perspectiva do MS, esses materiais, sobretudo a 'Cartilha para a mãe trabalhadora que amamenta' (BRASIL, 2010B), atendem a uma demanda por informações não somente das gestantes e lactantes, mas, também, dos próprios profissionais de saúde. Estes, a despeito do seu conhecimento técnico sobre o manejo da amamentação, não disporiam de informações suficientes acerca de como orientar as mães sobre seus direitos. 
Figura 1. Capa da 'Cartilha para a mãe trabalhadora que amamenta'

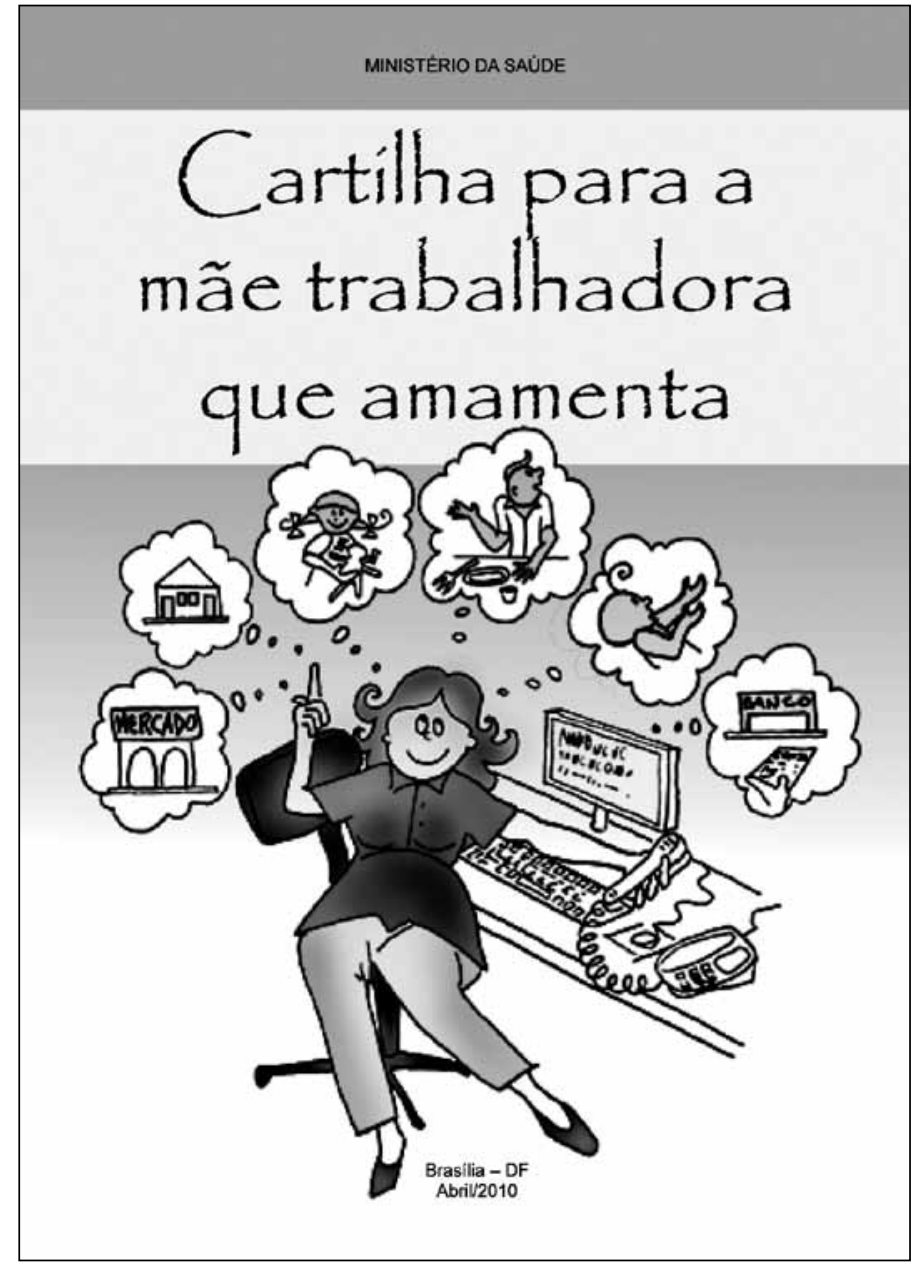

Fonte: BRASIL (2010B)

No intuito de minimizar essa lacuna, a Cartilha (BRASIL, 2010B) se dirige a mulheres que amamentam e devem retornar ao trabalho formal remunerado após a licença maternidade. Propõe-se a 'dar algumas respostas' às mães trabalhadoras sobre 'como dar de mamar e ao mesmo tempo trabalhar fora de casa', apresentando os direitos da trabalhadora que amamenta, reiterando a importância do aleitamento materno e orientando sobre como manter a amamentação após a volta ao trabalho. Desse modo, um de seus focos é esclarecer a mulher trabalhadora sobre seus direitos, informando sobre as garantias legais para famílias com filho(s): proteção à gestante contra demissão arbitrária (ou sem justa causa); obrigatoriedade de oferta de creches ou berçários (ou adoção do 'reembolso-creche') por empresas com 30 ou mais trabalhadoras maiores de 16 anos; direito a pausas para amamentar durante a jornada de trabalho; licença maternidade de 120 dias com remuneração integral; licença maternidade de seis meses (para funcionárias de empresas que aderiram à Lei $\mathrm{n}^{0} 11.770 / 2008$ e funcionárias públicas de estados e municípios que adotaram a licença estendida); extensão da licença maternidade por indicação médica; e licença paternidade de cinco dias. 
Na ilustração da capa da Cartilha (BRASIL, 2010B), uma mulher está sentada à mesa de trabalho, com o corpo virado para o lado e exibindo balõezinhos de pensamento com desenhos de diversas situações em volta da sua cabeça. Com uma mão, segura um telefone, e, com a outra, aponta para cima, como se lembrasse de alguma pendência. A imagem é bastante sugestiva sobre a situação da mulher-trabalhadora-mãe-que-amamenta: mesmo no ambiente de trabalho, ela teria a cabeça povoada por uma série de 'temas' ou 'questões', englobando os cuidados com o bebê e os filhos mais velhos, a relação com o marido e a administração da casa - com compras de mercado e contas a pagar. Ainda assim, a mulher aparece sorridente na imagem, dissimulando eventual transtorno decorrente da necessidade de conciliar tantas atribuições. Não há espaço para discussão sobre a possibilidade de a mulher, diante de inúmeras demandas, escolher a alimentação artificial do seu bebê. De acordo com Taylor e Wallace (2012, P. 85), restaria à mulher que não amamenta ou interrompe $\mathrm{o}$ aleitamento por limitações físicas ou necessidades pessoais lidar com a culpa ou a vergonha diante do julgamento moral da sociedade por colocar em risco a saúde do seu bebê. Para as autoras, a mensagem dos discursos pró-aleitamento "de que todas as mulheres podem amamentar implica que qualquer mulher que não consiga ou não o faça seja vergonhosa, uma mulher incompleta".

Figura 2. Página interna da 'Cartilha para a mãe trabalhadora que amamenta'

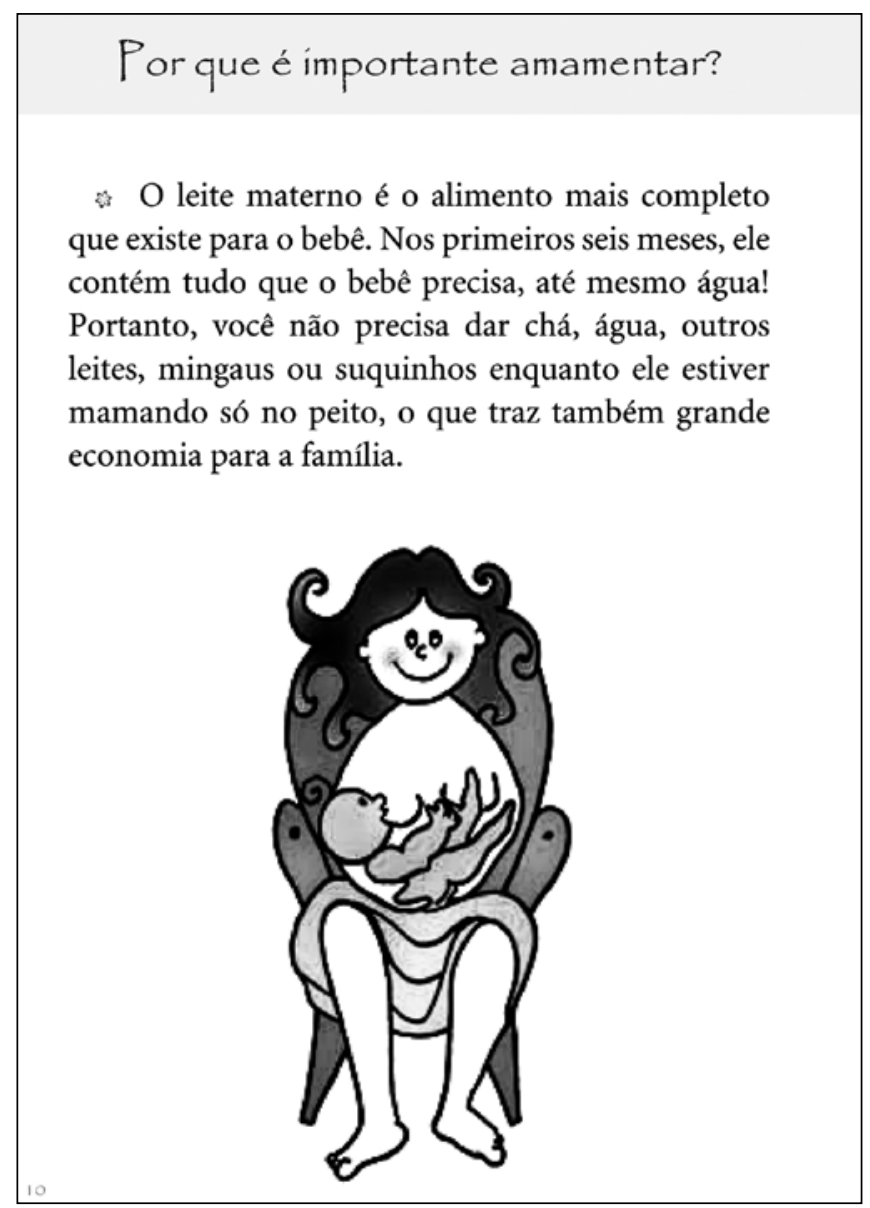


O foco nas qualidades do leite materno como produto e sua relevância para o estabelecimento e a manutenção da saúde da criança também pode ser observado em diversos trechos do material. Um exemplo é a seção: Por que é importante amamentar? Nela, são citados nove motivos pelos quais o documento considera importante amamentar. Destes, cinco se relacionam a qualidades relacionadas, especificamente, ao leite materno: alimento mais completo que existe, fácil de digerir, prático (está sempre pronto para o consumo), protege o bebê contra muitas doenças e diminui as possibilidades de problemas alérgicos, respiratórios e doenças, como diabetes, obesidade, entre outras. Das quatro restantes, três se referem a vantagens para a saúde orgânica da mãe: diminuição das chances de ocorrência de cânceres de mama e ovário e de diabetes, favorecimento da contração do útero materno, diminuindo perdas sanguíneas e anemia após o parto e maior facilidade para perder o peso adquirido durante a gravidez. O outro benefício apontado diz respeito à saúde do bebê, mas referindo-se à atividade de mamar e destacando a importância da sucção como exercício para desenvolvimento da face, contribuindo para que a criança tenha dentes bonitos, boa fala e respiração.

Para além dos aspectos objetivos da situação de retorno da mulher às atividades profissionais após o nascimento do bebê (sensibilização de chefia e colegas no ambiente de trabalho, estocagem de leite materno e treinamento do cuidador substituto para fornecê-lo à criança), o documento não aciona os sentidos da amamentação como relação que se estabelece entre as subjetividades de mãe e bebê. Esse aspecto da prática aparece somente em um momento: quando menciona "o contato físico, o carinho, o estímulo" (BRASIL, 2010B, P. 2) que a mãe sonha em dar para a criança e que a amamentação lhe permitiria proporcionar. Aspectos sociais mais amplos da vida da mulher-trabalhadora-mãe-que-amamenta ou 'sintomas' de origem emocional que possam acometer o bebê ou a mãe quando se aproxima o fim da licença maternidade e o momento da volta desta última ao trabalho não são abordados no material. Omitindo possíveis dificuldades da mulher - e mesmo da criança - em manter a amamentação após a retomada da rotina profissional pela mãe, a Cartilha (BRASIL, 2010B) silencia a problemática do desmame.

Com relação à linguagem utilizada no material, ressalta-se o uso de verbos no tempo presente e, de modo geral, na forma imperativa, tratando-se de um discurso de 'comando', que busca produzir um 'efeito de verdade' e fazer com que o receptor adote, no futuro, o comportamento ou a atitude a qual tal enunciado expressa (PINTO, 1994). Tal recurso fica evidente, por exemplo, no quadro "Algumas dicas", por meio de enunciados como: "Converse com o patrão para ver a possibilidade de você ter maior flexibilidade nos horários de trabalho", "Fale e explique ao seu patrão e seus colegas a importância de amamentar, explique especialmente que o leite materno protege seu filho", "Explique tudo isso também aos seus familiares" (BRASIL, 2010A, P. 4).

O folder "Apoio à mulher trabalhadora para manter a amamentação' (BRASIL, 2010A, P. 2) possui identidade visual semelhante à do material descrito anteriormente. Destinado a empresários, o material busca sensibilizar esse segmento da população para apoiar a mulher em fase de amamentação em suas empresas. Tal iniciativa parte do entendimento do MS de que, além das ações que já vinham sendo desenvolvidas no País, no âmbito da promoção, proteção e apoio ao aleitamento materno, "é preciso incorporar novas estratégias de apoio à amamentação envolvendo todos os setores da sociedade". A ilustração da capa, semelhante à da capa da Cartilha (BRASIL, 2010B), traz uma mulher-trabalhadora-mãe-que-amamenta sentada à sua mesa de trabalho, com acesso a computador e aparelho telefônico (na representação de 
uma profissional com certo grau de escolarização, cujo trabalho não pode ser considerado predominantemente físico), apontando o dedo para cima como se estivesse lembrando-se de algo. O que aparece no 'balãozinho' de pensamento é a imagem dela amamentando seu bebê. Daí, depreende-se que, mesmo no ambiente de trabalho, esta mulher está dividida entre trabalhar e amamentar seu/sua filho/a.

Figura 3. Folder 'Apoio à mulher trabalhadora para manter a amamentação' I

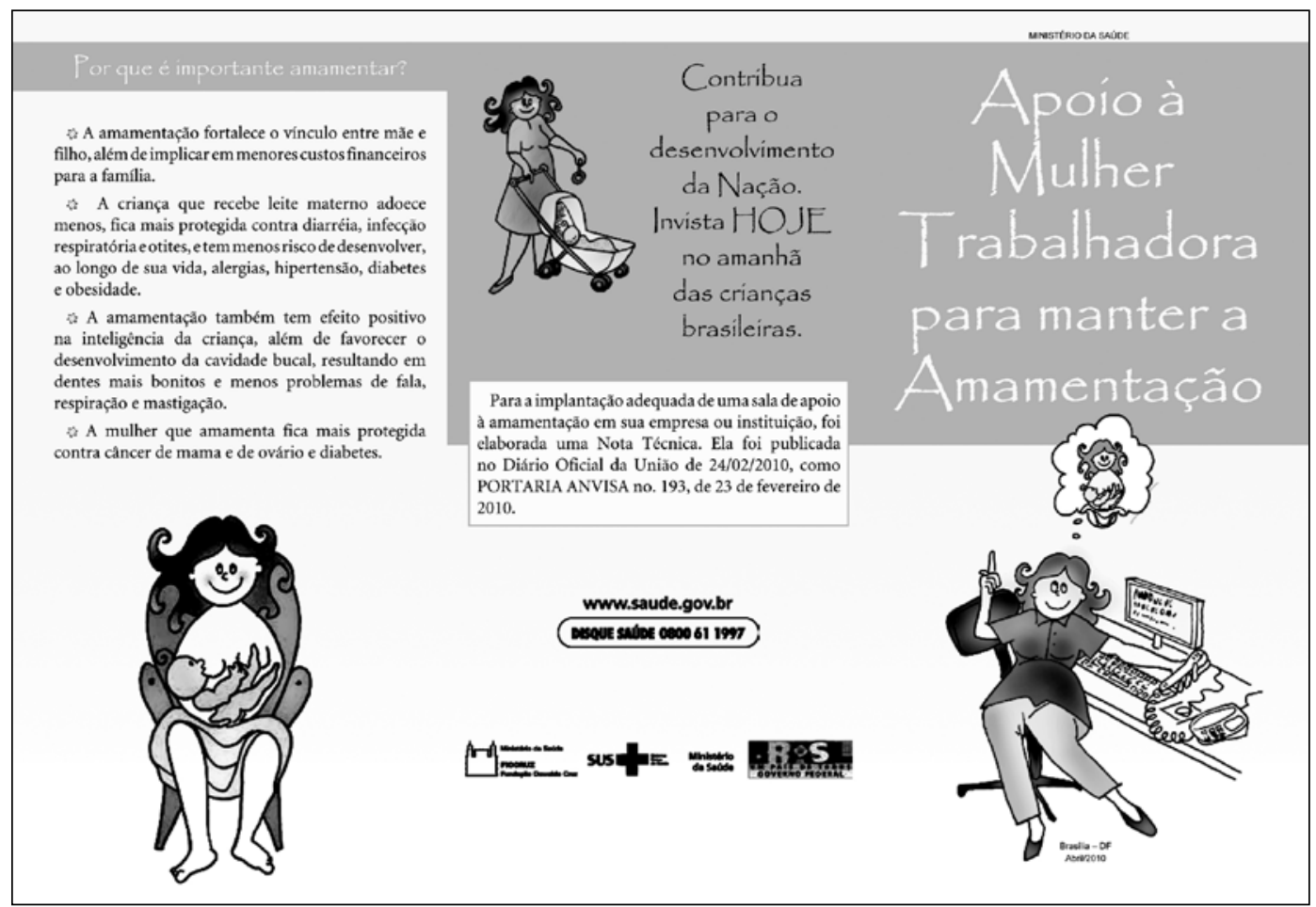

Fonte: BRASIL (2010A)

Além de citar alguns passos que o empresariado nacional poderia adotar para apoiar a amamentação, como respeitar as leis que protegem a prática e aderir à licença-maternidade de seis meses, o texto advoga a implantação de uma sala de apoio à amamentação na empresa, argumentando que o empresário também sairia ganhando "com o menor absenteísmo da funcionária, haja vista as crianças amamentadas adoecerem menos" (BRASIL, 2010A, P. 4). As salas de apoio à amamentação são concebidas como espaços que permitem à mulher retirar e estocar adequadamente $o$ leite materno em seus ambientes de trabalho.
O material reitera, ainda, as vantagens da amamentação/aleitamento materno para mãe, criança e família, e tem, na última página, um texto escrito em fonte maior e tom mais enfático e solene: "Contribua para o desenvolvimento da Nação. Invista HOJE no amanhã das crianças brasileiras". Tal trecho remete aos discursos do final do século XIX e das primeiras décadas do século XX, promovidos pelo movimento higienista, que relacionava $\mathrm{o}$ cuidado com os filhos à saúde da nação, vinculando a amamentação ao provimento de cidadãos fortes para a construção de uma nação moderna e próspera (MATOS, 2000). 
Figura 4. Folder 'Apoio à mulher trabalhadora para manter a amamentação' II

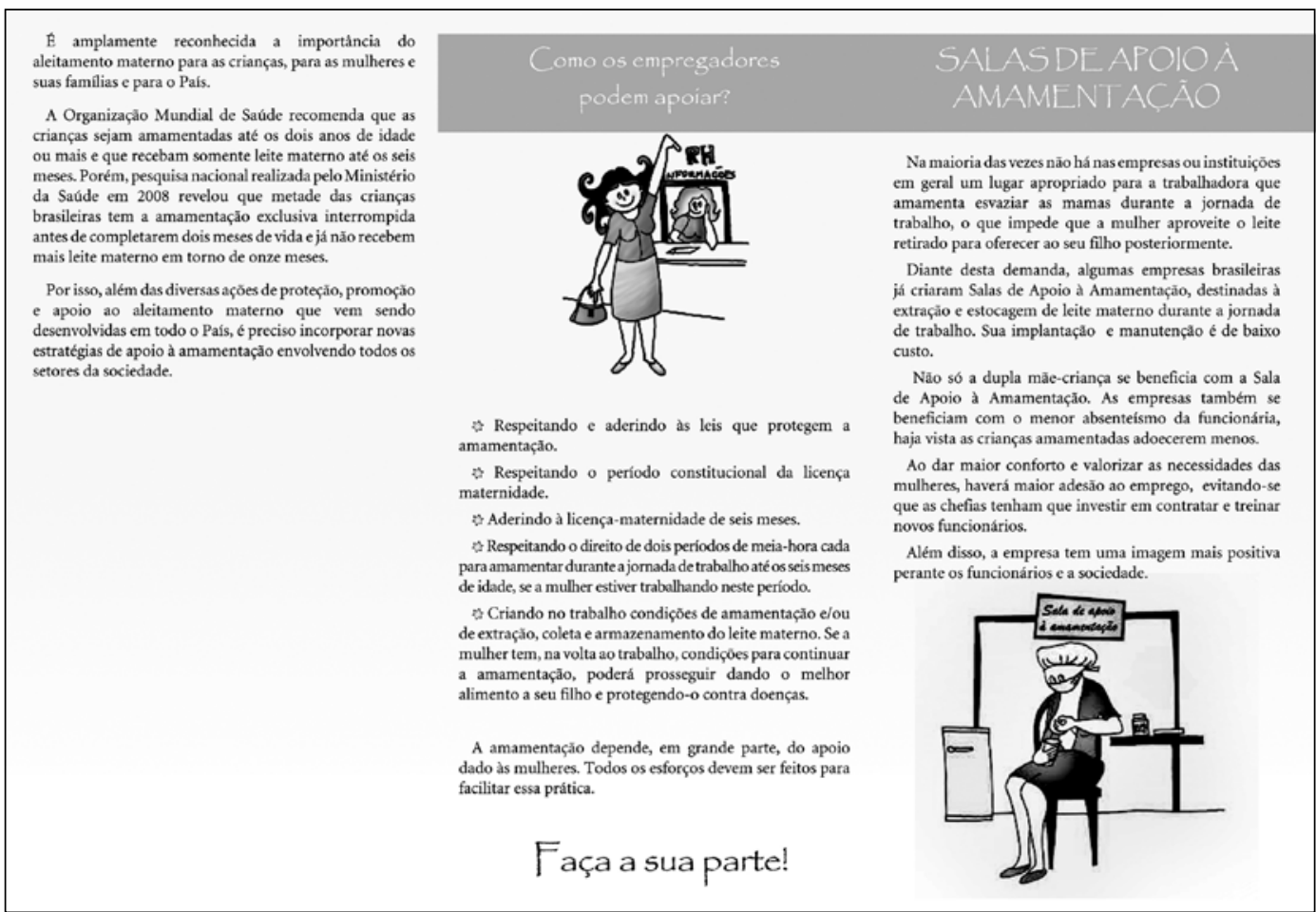

Fonte: BRASIL (2010A).

O gênero do substantivo utilizado para se referir aos empregadores é sempre o masculino, não somente nos materiais analisados como, também, na fala da entrevistada. Isso se verifica no tópico "Como 'os empregadores' podem apoiar?”, do folder (BRASIL, 2010A, P. 2, GRIFO NOSSO), nos enunciados "Converse com $o$ 'patrão' para ver a possibilidade de você ter maior flexibilidade nos horários de trabalho" e "Fale e explique 'ao seu patrão' e seus colegas a importância de amamentar" (BRASIL, 2010B, P. 4, GRIFOS NOSSOS). A questão do sexo do(a) empresário(a) - inclusive como fator que poderia interferir (negativa ou positivamente) na sua sensibilização para a causa - não é mencionada nos discursos desses materiais, mesmo com a ampliação da presença de mulheres no mercado formal de trabalho. No Brasil, entretanto, a escolha do gênero masculino do substantivo nos materiais reforça uma tendência real do mercado. Segundo pesquisa intitulada 'Mulheres nos negócios: o caminho para a liderança' (IBR, 2015), o País é o terceiro no mundo com a menor proporção de cargos de gestão seniores detidos por mulheres (15\%), empatado com a Índia e atrás apenas da Alemanha e do Japão. O estudo também elenca os fatores que influenciam a progressão na carreira de homens e mulheres, apontando que o cuidado da família exige mais sacrifícios da mulher.

Nesse sentido, o discurso do compromisso moral da mulher para com a amamentação da prole - como o proferido pelo folder - é indissociável daquele que reforça a divisão sexual do trabalho (na qual cabe ao homem o trabalho no mundo público e a manutenção financeira da família, e à mulher o cuidado com a família e a organização do espaço doméstico). Tal discurso se perpetua, ainda, em diversos momentos, nos materiais oficiais sobre aleitamento materno, a despeito da 
presença maciça da mulher no mercado de trabalho formal e informal. Afinal, no País, "quase $25 \%$ da população economicamente ativa é constituída por mulheres com filhos menores de seis meses de idade" (BRASILEIRO ET AL., 2012, P. 647). Os materiais analisados supõem saber o que a mãe deseja para o seu filho (BRASIL, 2010B) e preconizam que todos devem apoiar a amamentação (BRASIL, 2010A), dever da mulher, a qual precisa ser apoiada nessa empreitada. Mesmo na Cartilha (BRASIL, 2010B), a tônica dos discursos é de que cabe à própria mulher trazer as demandas familiares - no caso, relacionadas à alimentação do bebê para suas relações e ambiente de trabalho, sensibilizando chefe e colegas. A mensagem é inequívoca: o papel de mãe deve se sobrepor aos demais, inclusive ao de profissional, e a saúde do bebê é, mais do que uma complexa rede de condicionantes sociais, responsabilidade que recai, quase que exclusivamente, sobre a mulher.

\section{Discussão: alguns avanços e muitos desafios}

A despeito do incremento conquistado na prática do aleitamento materno no Brasil nos últimos quarenta anos, as taxas, principalmente as relacionadas à amamentação exclusiva, continuam, segundo Souza, Espírito Santo e Giugliani (2010), abaixo do recomendado pela Organização Mundial da Saúde (OMS). Para as autoras, os principais obstáculos para que o País alcance os índices de aleitamento materno desejados incluem suas dimensões continentais, que implicam: diferenças regionais significativas; a dificuldade de sensibilização, tanto de gestores e profissionais de saúde quanto da população em geral, sobre a importância da promoção do aleitamento materno; a escassez de recursos humanos com qualificação para esse trabalho; e o abandono do aleitamento materno após o final ou mesmo durante a licença-maternidade. Tais obstáculos evidenciam, segundo elas, a necessidade de investir em novas políticas e estratégias que viabilizem a amamentação.

Sobre o abandono da amamentação pelo retorno ao trabalho, parece razoável afirmar que a adoção de novas estratégias de incentivo à amamentação deveria incluir a problematização da questão do trabalho feminino e das políticas familiares, apontando contradições da política de promoção, proteção e apoio à amamentação, que permanecem pouco exploradas nos discursos contemporâneos pró-aleitamento materno. Observase, por exemplo, uma diferença fundamental entre os discursos a favor da utilização de fórmulas na alimentação de lactentes, difundidos até a década de 1970, e os discursos anteriores e posteriores a eles (tanto no higienismo quanto no retorno do incentivo ao aleitamento materno, a partir do final dos anos 1970). Enquanto os primeiros tinham como contexto a segunda onda feminista, a difusão da pílula anticoncepcional e a regulamentação do trabalho feminino no País, voltando sua atenção, principalmente, para a liberdade da mulher, os discursos pró-aleitamento materno concentram seu foco na criança e secundarizam qualquer obstáculo experimentado pela mulher, especialmente a trabalhadora, na prática da amamentação (AMORIM, 2008).

No entanto, diversos autores chamam atenção para os limites e possibilidades contemporâneas de conciliação entre a amamentação e a função materna como concebida na atualidade, por um lado, e o investimento da mulher na carreira, por outro. Essa relação tem sido analisada, por exemplo, na perspectiva de como o trabalho de meio período seria uma estratégia para auxiliar as mulheres a combinar amamentação e emprego (FEIN; ROE, 1998), muito improvável para aquelas mulheres que são chefes de família e não podem abrir mão de importante parcela da renda; ou de como a ampliação da licença maternidade, mudanças no ambiente de trabalho e leis específicas de proteção à mulher que 
amamenta poderiam beneficiar os índices de amamentação entre mulheres trabalhadoras (BRASILEIRO ET AL., 2012). Pesquisa realizada por Batista, Farias e Melo (2013, P. 132) também aponta associação positiva entre o fato de a mulher 'ser do lar' e a prática da amamentação exclusiva e um melhor cuidado com os filhos (em comparação com mães que trabalham fora de casa). Os autores ressaltam, no entanto, que o trabalho não impede a amamentação, dada a existência de alternativas "como a ordenha manual e a licença maternidade, para possibilitar à mãe uma maior dedicação ao seu filho e propiciar a prática do aleitamento materno". Nesses casos, entende-se o trabalho da mulher como um potencial obstáculo ou, ao menos, dificultador da amamentação.

Uma aproximação incomum é feita por Rippeyoung e Noonan (2009) sobre o foco do olhar acadêmico recair sempre sobre a influência negativa do trabalho da mulher no sucesso da amamentação. Os autores defendem que é preciso investigar se e como o aleitamento materno interfere no trabalho feminino, ou seja, se a relação opera, também, na direção oposta, argumentando que a prática de amamentar um bebê 'concorreria', em certa medida, com o retorno da mãe ao trabalho. Em função disso, muitas mulheres poderiam reduzir suas jornadas de trabalho, tirar licenças-maternidade mais longas, optar por um emprego mais compatível com a vida em família ou mesmo largar o trabalho em função da amamentação (situações mais frequentes em países como os Estados Unidos), o que acarretaria perdas econômicas para as famílias, além de desdobramentos negativos na trajetória profissional da mulher.

Nos materiais oficiais recentes de orientação ao aleitamento materno, no que se refere à contextualização das várias faces da mulher-mãe-que-amamenta, é notável que o trabalho feminino apareça tematizado somente nos materiais da Estratégia de Apoio à Mulher Trabalhadora que Amamenta, e que, mesmo neles, tal abordagem seja precária. A função de mãe é exposta como preponderante sobre os demais papéis assumidos pela mulher brasileira contemporânea, e o discurso se exime de problematizar os anseios e as expectativas, as condições de trabalho, salário e progressão profissional ou as dificuldades cotidianas de mulheres que optam ou, na maioria dos casos, precisam adotar a 'dupla jornada de trabalho', ou seja, acumular a participação nas esferas reprodutiva e produtiva (HIRATA; KERGOAT, 2007). É imprescindível pontuar essa questão porque os indicadores do trabalho precário demonstram que as mulheres são, inclusive, "mais numerosas do que os homens tanto no trabalho informal quanto no trabalho em parcial" (HIRATA, 2009, P. 26), sendo particularmente atingidas pela precarização social e do trabalho.

No que tange às políticas familiares brasileiras, que deveriam dar suporte às políticas voltadas à saúde da criança, da mulher e também do homem (que exerce, nesse caso, a função de pai e companheiro), há evidências de iniciativas que buscam dar condições sociais à aclamada 'amamentação exclusiva por seis meses' ou fazer emergir a reflexão mais sistemática sobre uma nova compreensão da paternidade e do lugar do pai no cuidado e na educação dos filhos. Nesse sentido, podem-se mencionar a aprovação e a regulamentação da ampliação da licença maternidade para seis meses para servidoras públicas federais (em 2008) e funcionárias de empresas privadas que aderirem ao Programa Empresa Cidadã (em vigor desde 2010); e a recente extensão da licença paternidade (para vinte dias consecutivos sem prejuízo do emprego e do salário) também para servidores da Administração Pública Federal e funcionários de instituições vinculadas ao Programa Empresa-Cidadã (Lei n ${ }^{0} 13.257 / 2016$ ).

\section{Conclusão}

A análise dos materiais da Estratégia de Apoio à Mulher Trabalhadora que Amamenta permite concluir que nem mesmo eles abordam, satisfatoriamente, as diferentes condições de trabalho 
da mulher e possibilidades de manter a amamentação para além da licença maternidade. Seus discursos continuam reforçando o dever da mulher de amamentar, recolocando-a na função materna e doméstica como seu principal papel social, tal qual exercido pelo discurso sanitarista da higiene nas primeiras décadas do século XX. Mais recentemente, passam a enfatizar também o caráter prático e 'econômico' do leite materno para a família, que pode prescindir de fórmulas 'maternizadas' e utensílios para ministrá-las. O aleitamento materno maciço converte-se em economia para o próprio Estado, que reduz os gastos com a compra de alimentos industrializados para manutenção de classes sociais menos favorecidas.

Entretanto, a política oficial não leva em consideração os 'custos' da amamentação. Não se discute o montante de recursos que, sobretudo o Estado, mas também as empresas despendem com as licenças ampliadas, nem quais são as repercussões quando uma mulher se afasta do mundo do trabalho assalariado - total ou parcialmente - para alimentar e cuidar pessoalmente da criança, com consequências para o orçamento familiar, às vezes, por períodos superiores a dois anos. Ao lado disso, a despeito de alguns avanços mencionados, as políticas familiares brasileiras continuam se mostrando insuficientes na resolução de questões relativas à conciliação do trabalho feminino remunerado com o trabalho representado não somente pelo aleitamento materno em si, mas pelo cuidado da família como um todo. Mais do que isso, elas acabam por ser, junto aos próprios discursos pró-aleitamento materno oficiais, corresponsáveis pela manutenção de um sistema de gênero no País que fortalece a divisão sexual do trabalho.

Se a saúde da criança é uma prioridade para o Estado brasileiro e o cuidado com seu desenvolvimento na chamada primeira infância, visto como tão primordial, é tempo de avançar em várias frentes por meio, entre outras coisas, de políticas familiares mais efetivas. A extensão das licenças maternidade e paternidade para todas as trabalhadoras e trabalhadores e a criação de licenças parentais, já existentes em países como Suécia e Portugal, podem representar um caminho para tornar mais equânime a divisão do bônus e do ônus oriundos da criação dos filhos entre mulheres e homens e desprecarizar, em alguma medida, a situação atual da mulher no mercado de trabalho.

\section{Colaboradores}

Irene Rocha Kalil redigiu o artigo, desdobramento de sua pesquisa de doutorado, concluída em 2015. Adriana Cavalcanti de Aguiar revisou e editou o artigo, na condição de orientadora. 


\section{Referências}

AMORIM, S. T. S. P. Aleitamento materno ou artificial: práticas ao sabor do contexto. Brasil (1960-1988).

Estudos Feministas, Florianópolis, v. 16, n. 2, p. 581-598, maio/ago. 2008.

BATISTA, K. R. A.; FARIAS, M. C. A. D.; MELO, W. S. N. Influência da assistência de enfermagem na prática da amamentação no puerpério imediato. Saúde em Debate, Rio de Janeiro, v. 37, n. 96, p. 130-138, jan./mar. 2013.

BESSE, S. K. Modernizando a desigualdade: Reestruturação da Ideologia de Gênero no Brasil 19141940. São Paulo: Edusp, 1999.

BRASIL. Lei ${ }^{\circ}$ 11.265, de 3 de janeiro 2006. Regulamenta a comercialização de alimentos para lactentes e crianças de primeira infância e também a de produtos de puericultura correlatos. Diário Oficial [da] República Federativa do Brasil, Poder Executivo, Brasília, DF, 4 jan. 2006. p. 1. Disponível em: <http:// www.planalto.gov.br/ccivil_03/_Ato2004-2006/2006/ Lei/L11265.htm>. Acesso em: 25 ago. 2016.

Lei $n^{\circ} 11.770$, de 9 de setembro de 2008. Cria o

Programa Empresa Cidadã, destinado à prorrogação da licença-maternidade mediante concessão de incentivo fiscal, e altera a Lei no 8.212, de 24 de julho de 1991. Diário Oficial [da] República Federativa do Brasil, Poder Executivo, Brasília, DF, 10 set. 2008. p. 1. Disponível em: <http://www.planalto.gov.br/ccivil_03/_ato20072010/2008/lei/l11770.htm>. Acesso em: 25 ago. 2016.

Lei $\mathrm{n}^{\circ}$ 13.257, de 8 de março de 2016. Dispõe sobre as políticas públicas para a primeira infância e altera a Lei no 8.069, de 13 de julho de 1990 (Estatuto da Criança e do Adolescente), o Decreto-Lei no 3.689 de 3 de outubro de 1941 (Código de Processo Penal... Diário Oficial [da] República Federativa do Brasil, Poder Executivo, Brasília, DF, 9 mar. 2016. p. 1. Disponível em: <http://www.planalto.gov.br/ccivil_03/_Ato20152018/2016/Lei/L13257.htm>. Acesso em: 25 ago. 2016.

BRASIL. Ministério da Saúde. Apoio à mulher trabalhadora para manter a amamentação. Brasília,
DF, 2010a. Disponível em: <http://bvsms.saude.gov. br/bvs/publicacoes/apoio_mulher_trabalhadora amamentacao.pdf>. Acesso em: 17 ago. 2016.

Cartilha para a mãe trabalhadora que amamenta. Brasília, DF, 2010b. Disponível em: <http://bvsms. saude.gov.br/bvs/publicacoes/cartilha_mae_ trabalhadora_amamenta.pdf > . Acesso em: 17 ago. 2016.

Gestões e gestores de políticas públicas de atenção à saúde da criança: 70 anos de história. Brasília, DF, 2011. Disponível em: <http://bvsms.saude.gov.br/bvs/ publicacoes/70_anos_historia_saude_crianca.pdf $>$. Acesso em: 20 ago. 2011.

BRASILEIRO, A. et. al. A amamentação entre filhos de mulheres trabalhadoras. Rev. Saúde Pública, São Paulo, v. 46, n. 4 , p. $642-648,2012$.

COSTA, J. F. Ordem Médica e Norma Familiar. 4. ed. Rio de Janeiro: Graal,1999.

FEIN, S. B.; ROE, B. The effect of work status on initiation and duration of breast-feeding. American Journal of Public Health, Nova York, v. 88, n. 7, p. 10421046, 1998

FLAQUER, L. Las políticas familiares em una perspectiva comparada. Barcelona: Fundación "la Caixa", 2000

\section{GRANT THORNTON INTERNATIONAL BUSINESS} REPORT (IBR). Women in business: the path to leadership. Londres, 2015. Disponível em: <http:// www.grantthornton.global/globalassets/1.-memberfirms/global/insights/ibr-charts/ibr2015_wib_report_ final.pdf>. Acesso em: 24 maio 2016.

HIRATA, H. A precarização e a divisão internacional e sexual do trabalho. Sociologias, Porto Alegre, ano 11, n. 21, p. 24-41, jan./jun. 2009

HIRATA, H.; KERGOAT, D. Novas configurações da divisão sexual do trabalho. Cadernos de Pesquisa, São Paulo, v. 37, n. 132, p. 595-609, set./dez. 2007. 


\section{INSTITUTO BRASILEIRO DE GEOGRAFIA E} ESTATÍSTICA (IBGE). Censo Demográfico 2010. Rio de Janeiro, 2010. Disponível em: <http://www.ibge.gov. br/home/estatistica/populacao/censo2010/resultados_ gerais_amostra/resultados_gerais_amostra_tab_uf_ microdados.shtm>. Acesso em: 17 ago. 2016.

MATOS, M. I. S. Em nome do engrandecimento da nação: representações de gênero no discurso médico: São Paulo 1890-1930. Diálogos, Maringá, v. 4, n. 4, p. 77-92, 2000

MOTT, M. L. Maternalismo, políticas públicas e benemerência no Brasil (1930-1945). Cadernos Pagu, Campinas, n. 16, p.199-234, 2001.

ORLANDI, E. P. Análise de Discurso: princípios e procedimentos. Campinas: Pontes, 1999.

PINTO, M. J. As marcas linguísticas da enunciação: esboço de uma gramática enunciativa do português. Rio de Janeiro: Numen, 1994.

\section{RIPPEYOUNG, P. L. F.; NOONAN, M. C. Is} breastfeeding truly free? The economic consequences of breastfeeding for women. In: 2009 Annual Meeting of Population Association of America. Detroit:
Princeton, 2009. Disponível em: <http://paa2009.

princeton.edu/papers/91391>. Acesso em: 13 ago. 2012.

ROMANI, J. P. Mulher: Natureza e Sociedade. In: LUZ, M. T. (Org.). O lugar da mulher: estudos sobre a condição feminina na sociedade atual. Rio de Janeiro: Graal, 1982. p. 59-71.

SOUZA, C. B.; ESPÍRITO SANTO, L. C.;

GIUGLIANI, E. R. J. Politique publique de soutien à l'allaitementmaternel: l'expérience du Brésil. La Santé de l'homme. São Maurício, n. 408, p. 34-36, 2010.

TAYLOR, E. N.; WALLACE, L. E. For shame: feminism, breastfeeding advocacy, and maternal guilt. Hypatia, Edwardsville, v. 27, n. 1, p. 76-98, 2012.

\section{VILLELA, W.; MONTEIRO, S.; VARGAS, E. A}

incorporação de novos temas e saberes nos estudos em saúde coletiva: o caso do uso da categoria gênero. Ciência \& Saúde Coletiva, Rio de Janeiro, v. 14, n. 4, p. 997-1006, 2009.

Recebido para publicação em maio de 2016

Versão final em agosto de 2016

Conflito de interesses: inexistente

Suporte financeiro: não houve 